\title{
The use of social media by UK local resilience forums
}

\author{
D. J. Meaton ${ }^{1} \&$ L. A. Stringer ${ }^{2}$ \\ ${ }^{1}$ University of Huddersfield, UK \\ ${ }^{2}$ Public Health England (formerly Health Protection Agency), UK
}

\begin{abstract}
The power of the public to capture and share real-time information has been utilised effectively in disaster situations, most notably Haiti, and social media has been important for developing new 'communities of interest', exemplified by its role during the Arab Spring. The potential methods of harnessing social media in the field of emergency planning, resilience and response (EPRR) are varied and interesting, and range from its use as a means of sending out public information to new ways of generating and using real-time data. Although the UK government have produced various guidance documents for the use of social media, the professional use of such technology in the UKEPRR field is poorly documented and appears sporadic. This paper presents the results of a survey of Local Resilience Forums in the UK on their use and engagement with social media. The findings suggest that the level of application of social media strategies as emergency planning or response tools varied significantly between the LRFs. While over $90 \%$ of respondents claimed that their LRF used social media as part of their strategy, most of this use was reactive or passive, rather than proactive and systematic. The various strategies employed seem to be linked most strongly to local expertise and the existence of social media 'champions' rather than to the directives and guidance emerging from government. The paper concludes by making policy recommendations concerning requirements for mandatory social media training within the emergency planning professions.
\end{abstract}

Keywords: social media, crowdmapping, crowdsourcing, emergency planning, resilience, emergency response, local resilience forum. 


\section{Introduction}

Social media is a rapidly developing communication tool that has become embedded in society, culture and everyday life (Paslawsky [1]; Proctor [2]; Dufty [3]; Hughes and Palen [4]). Individuals, groups, businesses and organisations use social media to collaborate and share various types of information.

The number of people who now carry a phone or device capable of capturing images and connecting to the internet is growing (Freifeld et al. [5]). This makes anybody carrying such a device a potential 'reporter' with a far reaching internet audience. The power to capture information and share it in real time has been demonstrated on many occasions in recent times, during disasters such as Haiti, and in times of political and social change, for example the Arab Spring (Cottle [6]). When governments place bans on live reporting and censor the mainstream media, social media provides a platform where information can still be shared (Doyle et al. [7]) and some argue that "the greatest contribution that social media has made to modern democracy is making information available at the touch of a mouse" (AllAfrica.com [8]).

The potential for using social media in the field of EPRR is broad and far reaching, providing opportunities that include assisting during the mitigation, response and recovery phases.

Palen et al. [9] point out the significance of photographs taken by eyewitnesses and shared using social media on disaster response. They are no longer seen as personal accounts but as evidence that is often requested by formal disaster response agencies. During emergencies the public actively seek information and the photographic evidence posted on image sharing websites such as FlickR can help people to make sense of the event. The photographic image itself can become a 'community' where people come together to share and comment on the content. Tobias [10] emphasises the power of the eyewitness 'citizen reporter' who will usually be at the scene of an incident long before the traditional media (and even emergency services) arrive. Iconic images such as the photograph taken of the plane ditching in the Hudson River and Tweeted within minutes of the incident were captured by the public and shared to provide information about an incident before emergency services or the media arrive. These 'citizen reporters' are also greater in number and are capable of representing a larger geographical area than traditional media reporters are (Heinzelman and Waters [11]).

The process of taking this information and presenting it geographically has been termed as 'Crowdmapping'. Software has been developed to assist in the process, born from the earlier deployments of Google maps (and others) that were then utilised within the social media community to create a representation of events. The information is often displayed in the form of flags displaying the location of the source onto a map. Software has been created to do this in a more structured and controlled manner, the most discussed in the literature, as it has been utilised in real life situations is Ushahidi [12]. 
'Crowdmapping' was demonstrated following the incident at the Fukushima Nuclear Power Plant where radiation maps were produced in Japan and the US (Saenz [13]). Similarly, the method was used in Oregon following a large 'boom'. A web developer who heard the 'boom' created a Google Map and asked people to plot on the map what the explosion had sounded like from their location. Within an hour 100 people had placed a pin which were colour coded, depending on the intensity of the noise heard with red being loudest. The police went to the scene concentrating on the area containing the highest concentration of red pins and found the remnants of an exploded pipe bomb (Tobias [10]).

Health organisations have widely used social media as a tool to broadcast public health messages and to educate the public. The Centres for Disease Control and Prevention (CDC) [14] in the USA recognise the potential of social media to "expand reach, foster engagement and increase access to credible, science based health messages". Although social media is widely used for seeking out information relating to health, examples of cases taking full advantage of iterative social media to improve public health are few. A number of exceptions include some epidemiologists who are attempting to use social media monitoring for accessing additional sources of data relating to flu-like illnesses (Corley et al. [15] and health professionals at CDC who used the online virtual world, Second Life, to facilitate training on H1N1 virus and to simulate mass prophylaxis sites and distribution of materials following an Anthrax attack (Crowe [16]). Vance et al. [17] also discuss the use of Second Life for providing health support and advice to patients.

More conventionally social media could be utilised by health organisations to target specific groups. For example, a forum frequented by parents could be targeted as a community who may benefit from specific health advice relating to child immunisation.

The opportunities offered by social media as a 'two way operational tool' are great, but in the UK EPRR field there is a lack of evidence regarding the use of social media and it seems that there is limited recognition of its potential and poor understanding of the drivers (or barriers) to its greater utilisation.

\section{Social media strategies}

The success of social media use is dependent on a well-designed strategy. Crowe [16] argues that social media has already impacted on emergency management and therefore it is imperative that emergency planning and response staff utilise the new technology in a proactive way. Lindsay [18] states that while EP communities understand how they can develop strategies to harness social media that they also need to do so with some urgency. St Denis et al. [19] point out that as social media use grows in the public domain the pressure on emergency managers to use these communication channels for information distribution is also increasing. It is reasonable to consider that as social media becomes more embedded in society the urgency for the EPRR field to adapt its strategies for communicating with the public will increase. 
However, in developing a social media strategy, those responsible may face obstacles within their organisation at the strategic level.

\subsection{Organisational 'buy-in'}

It has been suggested that the effective utilisation of social media tools are dependent on leadership style (Denyer et al. [20]), although Tobias [10] suggests that a lack of organisational buy in could also be due to a lack of confidence in the public generated information. St Denis et al. [19] point out that understanding social media strategy adoption is challenging due to its steep learning curve.

Obtaining organisational buy in is also discussed further by Tobias [10] who notes that a group of emergency managers "frequently mention methods for obtaining 'buy in' from those in their organisations who are not familiar with social media". This suggests that persuading the strategists within an organisation to develop social media plans, may be difficult if those making the decision to do so lack the technical knowledge and understanding required for them to appreciate how it might be utilised, and/or are distrustful of the technology.

The UK Home Office have produced Social Media guidance documents such as "Social Media Guidance for Civil Servants" [21] and The Defence Science and Technology Laboratory (DSTL) "Smart Tips for Category 1 Responders using social media in emergency management" [22] while the Cabinet Office will "begin a series of good practice seminars on using social media to interact with users on a rolling basis to December 2013" [23]. However, Proctor [24] suggests that the lack of set standards for emergency responders in the UK, and the consequential variation in the application of social media strategies poses an area of risk.

There appears to be recognition that those responsible for EPRR would benefit from directives to standardise how the community utilise social media, while guidance is appearing in the form of documents and workshops, the uptake may well be variable as it doesn't appear to be a mandatory requirement for Category 1 Responders to follow.

\subsection{Types of strategy}

Lindsay [18] categorises the current use of social media into two broad categories, a passive approach to disseminate information and receive feedback, with this being the most common approach taken to date by emergency responders and a second approach that involves the systematic use of social media as an emergency management tool.

Proctor [2] points out that the most obvious use of social media in relation to emergency management is to 'warn and inform'. As $60 \%$ of the public access the internet every day, social media tools should be used in every communications strategy for warning and informing the public.

Edwards [25] argues that EPRR can no longer just broadcast to individuals and communities and must instead devise strategies that are based on a two way 
model of communication, listening to what is being said by social media users and then using the communication channel to provide support and improve negatives. The literature appears to demonstrate a consensus that social media strategies need to be developed as a two way communication channel, with consideration as to how information will be received and used, along with how information will be sent.

It should be recognised however, that where some public sector organisational teams have already been 'streamlined', the implementation of a resource intensive strategy may be difficult and achieving organisational 'buy-in' may be more successful by proposing a phased approach to implementation, especially where understanding at the strategic level is an issue.

Crowe [16] found that emergency planning departments are often small, and therefore expecting staff to implement a full scale proactive utilisation of social media may be unrealistic without applying additional resources to the team.

Crowe points out that social media technology is a free resource which 'cuts out the middle man', as public sector organisations budgets are also streamlined this could be viewed as an important benefit (White [26]; Woodcock [27]). Taking this further, Proctor [28] and St Denis et al. [19] discuss the potential for a practice involving the recruitment of volunteers to monitor social media during emergencies to form VOST (Virtual Operations Support Team). There is currently a UK project "UK VOST" (Jennings [29]) that "aims to develop a model of VOST that Category 1 Responders can feel confident in, and that is able to add value to emergency response in the UK". This could potentially address the resource issues that may be faced by many organisations.

\subsection{The civil contingencies act}

The fields of social media and EPRR are both relatively new and developing arenas, and both are constantly changing to adapt to new emerging technologies and threats and adoption by EPRR organisations varies. In England and Wales, Local Resilience Forums have a statutory requirement under the Civil Contingencies Act 2004 (CCA) which states that Category 1 emergency responders must: "...establish and maintain effective multi-agency arrangements to respond to major emergencies, to minimise the impact of those emergencies on the public, property and environment, and to satisfy fully the requirements of the Civil Contingencies Act 2004". Part One of the CCA also specifies that Category 1 responders have a number of duties with regard to civil protection, including to: "Put in place arrangements to make information available to the public about civil protection matters and maintain arrangements to warn inform and advise the public in the event of an emergency" "Co-operate with other local responders to enhance co-ordination and efficiency" (Civil Contingencies Act 2004 - Part 1 [30]).

The effective use of Social Media as a bi-directional tool has the obvious potential to assist Category 1 responders in their requirement to discharge the above duty to 'warn and inform' the public. This is exemplified by Barbier et al. [31] who describe the technology as a facilitator of information sharing, interoperability and collaboration. Social media could therefore potentially offer 
major support for CAT1 duties. However, Crowe [16] points out that social media generated information is unfiltered and not subject to the usual review, change and bias of traditional media channels which normally ensures that the public receive clear and consistent information.

Some organisations with an emergency response role are utilising social media platforms to develop strategies to broadcast their civil protection messages to the public, both in the planning and response phases. Proctor [2] points out that those organisations that additionally monitor social media also benefit from the ability to correct any rumours or contradictory advice that may emerge following the broadcast of a public message. Proctor also argues that social media is "not suitable for broadcasting messages". He discusses that a message could be sent as effectively to the public via a traditional channel such as by radio, allowing the responder to then continue with their response. He states that using social media to simply deliver a health protection message results in a 'flurry' of response and debate that the responder then needs to monitor. Although this is a valid point, particularly where resources are an issue, it should be balanced with the other arguments that point out the value of monitoring the information that is being posted during an incident.

Social media could assist the Category 1 responder in their duty to "warn and inform' beyond the facility to broadcast a message to a subscribed or selected audience. There is clear evidence that the potential exists for social media to assist during an incident response (Palen et al. [9]), and that utilising social media to engage with the public could provide a rapid understanding of a situation as it develops. However, Jaeger et al. [32] point out that before, during and after a major disaster, co-ordination of the response is difficult due to the number of individuals and organisations who work together and the interoperability issues that inevitably arise. For example, Barbier et al. [31] reported that during the response to the Haiti crisis, government and nongovernment organisations worked together but difficulties arose in co-ordinating the response due to the lack of a common information system. This problem was addressed in the UK by the development of the National Resilience Extranet (NRE) Collaborate Application to facilitate information sharing between CAT1 organisations. However in order to use the NRE various licenses and training regulations have to be met and it there is a danger that some responders will not have the experience or confidence to use the system in the event of an emergency. In comparison, many of these people will use social media in their day to day life, therefore maintaining an up to date knowledge of the application. While social media cannot match the level of security for information shared via the NRE, the use of social media as a tool to share real-time, un-sensitive information between emergency planners could be considered, in support of their duty under the Civil Contingencies Act to co-operate and collaborate with each other.

\subsection{Public expectation}

The impact of social media on everyday life has led to the public anticipating that social media channels will be monitored by emergency response staff during 
an incident and in times of crisis, more and more people are likely to rely on social media to get information, connect with loved ones, seek help and provide assistance (Corbin [33]). In America, a Red Cross survey [34] found that $69 \%$ or those surveyed said that emergency responders should be monitoring social media sites in order to direct help as soon as possible and nearly half believe that any request for assistance they made would be already receiving a response. Along with this expectation that someone is 'listening' there is also the assumption that information will be directed to them. Tobias [10] points out that there is an expectation amongst the public that information will be pushed to them immediately and Crowe [16] found that they expect to get more information more quickly than through traditional channels. While the public are now communicating with each other in real time, sharing information socially, it seems that this shift in the way people communicate has changed their expectations with regards to how they receive information from other official channels.

In order to ensure that any information flow between the responding organisation and the public is trusted it is important to foster good relationships prior to any incident. Crowe discusses the long standing issues around trust and the public regarding information received from government representatives and explains that social media creates a higher trust factor for information, as people view and share information within their common network of friends, contacts or organisations. Jaegar et al. [32] point out that trust in the sources of information will influence the level of participation and action taken in response. Van Velsen et al. [35] concur "for many, source credibility is an important asset of information usefulness". Barbier et al. [31] point out that the level of trust in social media posts could be determined by fellow user feedback, for example the 'thumbs-up' or 'thumbs-down' along with user comments. Kamel Boulos et al. [36] reinforces this finding and argues that "reputation and trust, both of emergency management personnel and members of the public that provide the data are equally important".

The public perception of how emergency response teams utilise social media suggests that responders must quickly improve their engagement with social media in order to ensure the health and safety of the public. Consideration should also be given to the actions that responders can undertake to improve the communities' ability to self-respond to an incident and protect life. Inspired by the fact that following the Kobe earthquake $80 \%$ of victims were rescued by family and friends, which involved activating existing social ties, Jaeger et al. [32] discuss the concept of Community Response Grids as a method for increasing community resilience. Facilitating channels for providing information to the public to aid resident to resident assistance is an important avenue of improving the breadth of reach of any messages conveyed via social media.

\section{Survey}

Since there is so much potential for the use of social media within the EPRR community, it was considered important to know what policies and practices 
already existed within Local Resilience Forums and their partners. A questionnaire was distributed to all 38 Local Resilience Forum chairs on the 26th November 2012, with a request that it was cascaded at their discretion to the LRF partners. To ensure anonymity, but to gauge the responses geographically, the respondents were asked to log their LRF by region but not to identify the specific LRF.

There were a total of 63 responses; all were complete and included in the analysis. Due to the anonymity of the responses and the number of LRF in each region, it is impossible to determine exactly how many LRF are represented by this data, although it can be assumed that a maximum of $18 \mathrm{LRF}$ are represented by the respondents. It is not possible to say how many organisations are represented by the responses, however, they are categorised in terms of 'Responder Type' and 'Health'. The responses demonstrated that $75 \%$ of the LRFs use social media to communicate with the public, but only $35 \%$ use it to communicate with their partner organisations. $40 \%$ of those responding for the LRF were less sure about the social media monitoring strategy, with only $20 \%$ reporting that it is used.

The LRF responders also reported that the majority (60\%) have a strategy for social media use during an incident response, $25 \%$ reported that their LRF does not have such a strategy and the remainder were unsure.

Of those using social media during a response, the majority use it to both broadcast and monitor. What isn't clear is the detail of the monitoring strategy. This could be monitoring the responses to their own broadcasts, or monitoring what is being said regarding specific incidents or issues, or even to defer the monitoring and broadcasting back to the individual responding organisation.

Where it was reported that social media isn't presently used by an LRF, 50\% answered that they are 'Not Sure' or 'No' when asked if they had plans to implement in the future. The responses received on behalf of partner organisations showed that the majority were not sure how social media was being used. Although it is unreasonable to expect that all staff within an organisation will be aware of the social media activity, it would perhaps be useful to ensure that LRF representatives are aware of any activity to allow them to effectively contribute to any future LRF strategy.

The table below shows the responses submitted for all organisations.

Table 1: $\quad$ Responses on behalf of organisations.

\begin{tabular}{|l|c|c|c|}
\hline & Yes & No & Not sure \\
\hline Incident Response & $59 \%$ & $27 \%$ & $14 \%$ \\
\hline Monitor & $37 \%$ & $19 \%$ & $44 \%$ \\
\hline Broadcast & $92 \%$ & $8 \%$ & - \\
\hline Social Media Training Provided & $38 \%$ & $49 \%$ & $13 \%$ \\
\hline Total & $\mathbf{5 6 . 5 \%}$ & $\mathbf{2 5 . 7 5 \%}$ & $\mathbf{1 7 . 7 5 \%}$ \\
\hline
\end{tabular}

The survey responses suggest that the while most organisations are using social media as a broadcasting tool, far less are also monitoring the responses 
and providing training for staff. With regard to what defines the organisational social media use, although the majority cited the organisation, a significant number (33\%) stated that their strategy is driven by 'local champions or experts'.

While the data collected via the survey identified some interesting patterns, there are several factors that should be taken into consideration when interpreting the results. Firstly the survey was voluntary and therefore not all LRF were represented. The LRF chairs/sub chairs are most often blue light responding organisations, and it appears that some LRF chairs submitted responses on behalf of the LRF themselves (without disseminating onto colleagues). As such it is likely that the organisational response was not a balanced representation of the partner organisations.

\section{Discussion}

This study has successfully identified a number of potential opportunities, issues and risks relating to the use of social media by the EPRR health community in England.

Although implementing a full scale social media policy to support EPRR would be a positive development, it is likely to be resource intensive. Realistic and manageable strategies, in line with the available resources need to be developed as poorly developed or unsupported strategies could lead to greater risks to public health and safety and could undermine the reputation of the organisation. Therefore it is recommended that social media strategies should be realistic and allowed to evolve incrementally, particularly where issues surrounding technological understanding are present. One approach could be to use the technology to 'Warn and Inform' in line with the Cat 1 responder duty, while crucially ensuring that the expectations of the public are being met. Measures to address resource issues in more ambitious strategies could involve the use of volunteers as in the VOST project and during the crowdsourcing response to the Haiti earthquake. It could be suggested that an LRF or EPRR organisation could factor monitoring and crowdsourcing into their social media strategy by implementing a similar volunteer team.

The study has evidenced clear benefits and the potential of crowdmapping within EPRR strategy, but the lack of implementation appears to be due to low levels of understanding by those responsible for developing the strategies. Confident use of the technology is important, as it would be risky to rely on the deployment of a system if the skills and knowledge required utilise the technology were not evident in those required to use it.

The resources required to implement a social media strategy lie mainly in the form of 'people' as opposed to purchasing additional physical technology. Many monitoring applications are free and have the potential to improve situational awareness for incident managers during a response. However, embedding these into existing plans will be challenging. The research found that 'social media champions' are responsible for driving approximately a third of the responding LRF strategies, which could reflect a lack of understanding by those involved in strategy development. To provide assurance, social media strategy should not be 
dependent on the efforts and advice of local champions. These champions are important, but there needs to be a systematic method of cascading that information within organisations. Training is therefore a key issue that needs to be addressed before social media can be used reliably and effectively. It would certainly be a risk to rely on a strategy where those responsible were not competent or confident to follow the plan, equally it would be inefficient to train staff to use a technology that they may not utilise and then forget how to use. This suggests that before a set of mandatory requirements for social media use within LRF can be suggested, the vast majority of the LRF partner organisations must adopt a strategy as part of their EPRR. The directives may come from the 'top down', but for them to be successful the training and day to day use needs to come from the 'bottom up'.

\section{References}

[1] Paslawsky, A., "The growth of social media norms and government's attempts at regulation", Fordham International Law Journal, vol. 35, no. 5, pp. 1485,2012

[2] Proctor, B., 'Get in Stay In Tweet' Digital Skills for Emergencies and Resilience Blog: available at http://www.benproctor.co.uk/blog/2011/ 03/02/get-in-stay-in-tweet/ 2011

[3] Dufty, N., 'Using Social Media for Natural Disaster Resilience' Kindle Book 2011

[4] Hughes, A and Palen, L., 'Twitter Adoption and Use in Mass Convergence and Emergency Events' Proceedings of the 6th International ISCRAM Conference - Gothenburg, Sweden, May 2009 J. Landgren and S. Jul, eds. 2009

[5] Freifeld CC, Chunara R, Mekaru SR. et al. Participatory epidemiology: use of mobile phones for community-based health reporting. PLoS medicine. 2010;7:e1000376, 2010

[6] Cottle S. 'Media and the Arab uprisings of 2011: Research notes'. Journalism. 2011;12:647-659, 2011

[7] Doyle M, Marsh L and Marsden, J., "Stigmergic self-organisation and the improvisation of Ushahidi SciVerse" - Science Direct Cognitive Systems Research 21 (2013) 52-64

[8] AllAfrica.com. (2012). 'Social media and social exchange theory and strategic contingencies theory, 2012

[9] Palen L, Vieweg S, Liu B, Hughes L., 'Crisis in a Networked World Features of Computer-Mediated Communication in the April 16, 2007, Virginia Tech Event' ConnectivIT Lab, University of Colorado, Boulder http://phildev.iupui.edu/summit2009/docs/Crisis\%20in\%20a\%20Networke d\%20World.pdf 2009

[10] Tobias, E., "Using Twitter and other social media platforms to provide situational awareness during an incident", Journal of business continuity and emergency planning, vol. 5, no. 3, pp. 208, 2011. 
[11] Heinzelman J and Waters C., 'Special Report Crowd sourcing Crisis Information in Disaster-affected Haiti' United States Institute of Peace http://www.usip.org/files/resources/SR252\%20-\%20Crowdsourcing\%20 Crisis\%20Information\%20in\%20Disaster-Affected\%20Haiti.pdf 2010

[12] http://ushahidi.com/

[13] Saenz, A., 'Japan's Nuclear Woes Give Rise to Crowd-Sourced Radiation Maps in Asia and US' Posted: 03/24/11 12:00 PM http://singularityhub. com/2011/03/24/japans-nuclear-woes-give-rise-to-crowd-sourcedradiation-maps-in-asia-and-us/ 2011

[14] CDC 'The Health Communicators Social Media Toolkit' http://www.cdc.gov/socialmedia/tools/guidelines/pdf/socialmediatoolkit_b m.pdf 2010

[15] Corley CD, Cook, DJ, Mikler AR and Singh KP., 'Text and Structural Data Mining of Influenza Mentions in Web and Social Media' International Journal of Environmental Research and Public Health ISSN 1660-4601 www.mdpi.com/journal/ijerph 2010

[16] Crowe, A., "The social media manifesto: a comprehensive review of the impact of social media on emergency management", Journal of business continuity and emergency planning, vol. 5, no. 1, pp. 409, 2011

[17] Vance, K Howe, Robert P. Dellavalle 'Social Internet Sites as a Source of Public Health Information' Dermatol Clin 27 133-136 doi:10.1016/j.det. 2008.11.010 0733-8635/08/\$ - see front matter a 2009 Elsevier Inc. http://pipedreamer.org/ tim/sources/vance200904DC.pdf 2009

[18] Lindsay, B, Social Media and Disasters, Current uses, future options and policy considerations - CRS Report for Congress : Kindle Book 2011

[19] St Denis et al. 'Trial by Fire: The Deployment of Trusted Digital Volunteers in the 2011 Shadow Lake Fire": Proceedings of the 9th International ISCRAM Conference - Vancouver, Canada, April 2012 http://epic.cs.colorado.edu/wp-content/uploads/TrustedDigitalVolunteers StDenis HughesPalen.pdf, 2012

[20] Denyer, D., Parry, E. and Flowers, P., "Social", "Open" and "Participative"? Exploring Personal Experiences and Organisational Effects of Enterprise 2.0 Use", Long Range Planning, http://www.sciencedirect.com.libaccess.hud.ac.uk/science/article/pii/S0024 630111000483, 2011

[21] Cabinet Office, Social Media Guidance for Civil Servants https://www.gov.uk/government/publications/social-media-guidance-forcivil-servants 2012

[22] DSTL smart tips for category 1 responders using social media in emergency management March 2012 https://whitehall-admin.production.alphagov.co. uk/government/uploads/system/uploads/attachment_data/file/85946/Usingsocial-media-in-emergencies-smart-tips.pdf 2012

[23] Cabinet Office 'Digital Strategy' http://www.cabinetoffice.gov.uk/sites/ default/files/resources/Cabinet-Office-Digital-Strategy-20-12-12.pdf 2012

[24] Proctor, B., 'Suggestions for minimum practice for social media in emergencies’ Digital Skills for Emergencies and Resilience Blog: available 
at http://www.benproctor.co.uk/blog/2011/11/29/suggestions-for-minimumpractice-for-social-media-in-emergencies/, 2011

[25] Edwards, C., (2009) 'Resilient Nation' Continuity Central http://www.continuitycentral.com/ResilientNation.pdf

[26] White, C., Social Media, Crisis Communication, and Emergency Management CRC Press : Kindle Book 2012

[27] Woodcock, J., 'Leveraging Social Media to Engage the Public in Homeland Security' Naval Postgraduate School Monterey California, Kindle Book 2009

[28] Proctor, B., 'Getting volunteers to monitor digital spaces in emergencies': Digital Skills for Emergencies and Resilience Blog: available at http://www.benproctor.co.uk/blog/2012/08/09/getting-volunteers-tomonitor-digital-spaces-in-emergencies/ 2012

[29] Jennings, S., 'Connecting People During an Emergency' VOST UK available at http://www.vostuk.org/intranet/ 2012

[30] Cabinet Office Civil Contingencies Act' available at: http://www.cabinet office.gov.uk/content/civil-contingencies-act

[31] Barbier G, Zafarani R, Gao H, Fung G, Liu H., Maximizing benefits from crowdsourced data. Computational and Mathematical Organization Theory; $18: 257-279,2012$

[32] Jaeger, P.T., Shneiderman, B., Fleischmann, K.R., Preece, J., Qu, Y. and Fei $\mathrm{Wu}, \mathrm{P} .$, "Community response grids: E-government, social networks, and effective emergency management", Telecommunications Policy, vol. 31, no. 10, pp. 592-604, 2007

[33] Corbin, K., "Tapping Social Media in Disasters: Dell partners with the American Red Cross to furnish it with technology dedicated to monitoring social media activity to improve emergency response and disaster recovery operations", CIO, vol. 25, 2012

[34] American Red Cross 'Web Users Increasingly Rely on Social Media to Seek Help in a Disaster' http://newsroom.redcross.org/2010/08/09/pressrelease-web-users-increasingly-rely-on-social-media-to-seek-help-in-adisaster/ 2010

[35] Van Velsen L, van Gemert-Pijnen JE, Beaujean DJ, Wentzel J, van Steenbergen JE., 'Should Health Organizations Use Web 2.0 Media in Times of an Infectious Disease Crisis? An In-depth Qualitative Study of Citizens' Information Behaviour during an EHEC Outbreak.' J Med Internet Res. 2012 Dec 20; 14(6):e181. doi: 10.2196/jmir.2123. available at: http://www.jmir.org/2012/6/e181/ 2012

[36] Kamel Boulos MN, Resch B, Crowley DN. et al. Crowdsourcing, citizen sensing and sensor web technologies for public and environmental health surveillance and crisis management: trends, OGC standards and application examples. International journal of health geographics.;10:67-67, 2011 